\title{
Stem cell nebulization therapy for COVID- 19 infection: radiological and clinical outcomes
}

\author{
Gina M. Torres Zambrano* (D), Yasmine Maher Ahmed, Yendry Ventura Carmenate and Momena Essam Elsadawy
}

\begin{abstract}
Background: SARS-CoV-2 is a highly contagious virus that spread worldwide with a rapid increase in the number of deaths. In March 2020, the WHO declared SARS-CoV-2 a pandemic. The primary diagnostic test is reverse transcription-polymerase chain reaction, but chest X-ray and computed tomography have become the typical diagnostic tools used to detect abnormal lung changes. Within the framework of the SENTAD COVID Study clinical trial, an observational and analytical study was conducted, where the patients received nebulization therapy with the use of autologous stem cells (group A) compared to the control arm (group B). Both groups received the UAE SARS-CoV-2 standard management. Radiological images of each patient were collected within $24 \mathrm{~h}$ of inclusion in the trial and during follow-up. Herein, we describe and evaluate the radiological findings and outcomes.

Results: A total of 139 subjects were included in our analysis, 69 in group A and 70 in group B. The most common finding was ground glass opacifications, followed by patchy consolidations, with $20 \%$ normal radiological images scored 3 from admission until discharge $(p<0.0001)$. Our results suggest a significant improvement in radiological images after treatment secondary to the stem cell effect of reducing inflammation and stimulating the pneumological healing process.

Conclusions: The use of novel therapies, such as stem cells, shows efficacy not only in terms of the control of clinical and paraclinical signs but also in the radiological changes described in the disease.

Trial registration: Study evaluating the safety and efficacy of autologous non-hematopoietic peripheral blood stem cells in COVID-19. Trial registration number: NCT04473170. Date of registration: 16 July 20202. Retrospectively registered.
\end{abstract}

Keywords: COVID-19, Radiological findings, Chest X-ray, Chest computed tomography, Stem cell nebulization

\section{Background}

In December 2019, severe acute respiratory syndrome coronavirus 2 (SARS-CoV-2) appeared in Wuhan, China. In March 2020, the World Health Organization (WHO) declared SARS-CoV-2 a pandemic. SARS-CoV-2 is a highly contagious virus that spread worldwide with a rapid increase in the number of deaths. It is characterized by fever, sore throat, body aches, dry cough, and

\footnotetext{
*Correspondence: Dr.torresz@gmail.com
}

Ain Shams University, Cairo, Egypt dyspnoea. Globally, as of 14 December 2020, 70.829.855 cases had been confirmed, including 1.605 .091 (2.22\%) deaths reported to the WHO. In the United Arab Emirates (UAE) from the 3rd of January to the 14th of December 2020, 184.949 cases were confirmed, with 617 deaths $(0.33 \%)[1,2]$.

Reverse transcription-polymerase chain reaction (RTPCR) is the most widely used diagnostic test due to its high sensitivity (between 56 and 83\%) and the low probability of false positives, but the predictive value of the test varies over time, having a $100 \%$ false negative rate at the time of exposure, which decreases at symptom onset

\section{Springer Open}

(c) The Author(s). 2021 Open Access This article is licensed under a Creative Commons Attribution 4.0 International License, which permits use, sharing, adaptation, distribution and reproduction in any medium or format, as long as you give appropriate credit to the original author(s) and the source, provide a link to the Creative Commons licence, and indicate if changes were made. The images or other third party material in this article are included in the article's Creative Commons licence, unless indicated otherwise in a credit line to the material. If material is not included in the article's Creative Commons licence and your intended use is not permitted by statutory regulation or exceeds the permitted use, you will need to obtain permission directly from the copyright holder. To view a copy of this licence, visit http://creativecommons.org/licenses/by/4.0/. 
from 20 to $38 \%$ [3-5]. Among the paraclinical findings, a normal or decreased total WBC count and lymphopenia are found, and elevated liver enzymes, $\mathrm{LDH}$, and Creactive protein are negative prognostic factors. In critically ill patients, the value of D-dimer increases, which is associated with a multi-organ imbalance [6-8].

Many studies have reported the clinical characteristics of SARS-CoV-2 and abnormalities found in chest imaging, where chest computed tomography (CT) and chest radiography (CXR) have become routine diagnostic tools used to detect abnormal lung changes [6, 9-11].

The role of these images in the detection and diagnosis of SARS-CoV-2 is still debatable. The latest American College of Radiology (ACR) criteria should be considered, taking into account that the findings are nonspecific and overlap with other viral infections, such as hemagglutinin type 1 and neuraminidase type 1 (H1N1), Middle East respiratory syndrome (MERS), and severe acute respiratory syndrome (SARS). The first-line imaging investigation for the diagnosis and follow-up of suspected and confirmed SARS-CoV-2 cases is CXR, which itself is not diagnostic but will help with clinical suspicion while awaiting PCR results $[10,12]$.

The most common radiological findings described include ground glass opacities (GGOs), patchy consolidation, air bronchogram, crazy pavement pattern, linear opacities and thickening or distortion of the bronchial wall, pleural effusion, and lymphadenopathy. Furthermore, it is essential to keep in mind that there is a relatively common number of normal radiological studies, particularly in early-stage or asymptomatic cases [11].

Using autologous peripheral blood non-hematopoietic enriched stem cells (PBNHESCs), the research team at the Abu Dhabi Stem Cell Center (ADSCC) developed a supportive treatment for SARS-CoV-2 (clinical trial of the "SENTAD COVID Study") [13].

In this article, we analyzed the radiological changes observed in CXR and chest CT performed in the two groups, one after receiving treatment and the other after being recruited as a control.

\section{Objective}

The aim of this study was to describe the radiological findings and outcomes in patients with SARS-CoV-2 before and after intervention within the framework of the ADSCC SENTAD COVID clinical trial in the Emirate of Abu Dhabi during April 2020.

\section{Methods}

Within the framework of the SENTAD COVID Study clinical trial [13], we performed a multi-center, prospective, analytical study to determine the radiological findings and outcomes in patients after the intervention. Four different hospitals from the Emirate of Abu Dhabi participated: Sheikh Khalifa Medical City, Al Rahba
Hospital, Al Mafraq Hospital, and Al Ain Hospital. From the main study, a total of 139 patients were divided into 2 groups for comparison (Fig. 1):

1. Group A (experimental arm) SARS-CoV-2 standard treatment plus nebulization with PBNHESCs $(n=69)$

2. Group B (no intervention arm) received standard SARS-CoV-2 treatment $(n=70)$

Both groups met the following inclusion criteria: aged $\geq 18$ years, laboratory confirmed SARS-CoV-2 infection, interstitial lung change in computed tomography, hospitalized and symptomatic patients, referring one or more symptoms, ability to complete blood collection and test requirements, and agreement to participate in the study.

Patients meeting any of the following criteria were excluded: a diagnosis of any type of shock, organ transplantation in the past 3 months, current immunosuppressive therapy, a diagnosis of hepatitis B virus (HBV) infection, human immunodeficiency virus (HIV) infection or acquired immunodeficiency syndrome (AIDS), a current diagnosis of cancer or a history of malignancies in the past 5 years, pregnancy or lactation, participation in other clinical trials in the past 3 months, an inability to complete blood collection and test requirements, or an inability to provide informed consent.

\section{Randomization}

The study registration/enrolment procedure is found in the data registration system. Fifty patients were expected for each group if there was no resizing of the sample. Randomization was performed to assign the SENTADCOVID study participants to maintain a balance between the treatment groups. Each "block" had a specific number of randomized treatment assignments. For example, for study groups A and B, the ADSCC research team planned to enrol 10 new patients per week.

Patients were assigned a treatment based on a specified randomized option for the week, having five As and five Bs within each block, so that at the end of each week there was a balance between the two arms of treatment. If the clinical trial had been completed, e.g., after having enrolled 54 patients, it might not be an exact balance, but it would be close.

All demographic characteristics, vital signs, biochemical studies, and radiological images of each patient were collected within $24 \mathrm{~h}$ of inclusion in the trial. The WHO ordinal scale for SARSCoV-2 from 1 to 8 was used to determine the clinical severity of the illness (Table 1) [14].

Both groups received standard SARS-CoV-2 treatment following the "UAE National Guidelines for Clinical Management and Treatment of SARS-CoV-2, v.2.0" according to the Department of Health (DOH) [2]. For group A patients, therapy with autologous stem cells PBNHESC-C 


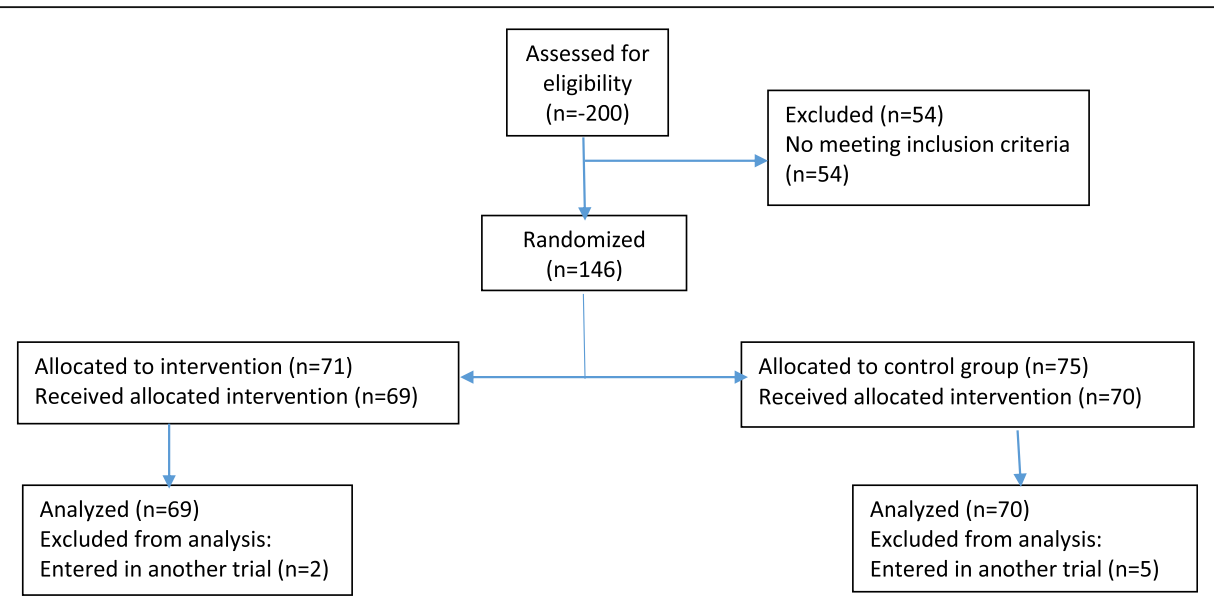

Fig. 1 CONSORT flow diagram

(cocktail rich in very small embryonic stem cells (VSEL) and growth factors derived from platelet-rich plasma (commercially called UAE Cell 19) was administered in two nebulizations of $10 \mathrm{cc}$. In two consecutive days (at least $22 \mathrm{~h}$ between each sample collection), withdrawal of $300 \mathrm{cc}$ of whole blood was performed and processed at the ADSCC laboratory, with characterization of cells by flow cytometry and automated inverted fluorescence microscopy.

Chest X-ray was performed for 100 cases (32 from group $\mathrm{A}$ and 68 from group $\mathrm{B}$ ) after confirming respiratory signs using a Samsung GF50 X-ray unit in ADSCC, portable GE definition Amx 700 and fixed GE discovery 650 in Sheikh Khalifa Medical Center. Forty CT scans (37 from group A and 3 from group B) were performed according to the critical criteria indicated using GE 46 MSCT. Both groups were followed up until discharge, and control radiological image reports were taken for further analysis.

\section{Statistical analysis}

A non-normal distribution of the variables was found, so non-parametric statistical methods were used. A test of

Table 1 SENTADO-COVID study seven-category ordinal scale for clinical involvement

\begin{tabular}{ll}
\hline Category & Score \\
\hline No limitation of activities, discharged from hospital & 1 \\
Limitation of activities. & 2 \\
Hospitalized, no oxygen therapy. & 3 \\
Oxygen by mask or nasal prongs. & 4 \\
Non-invasive ventilation or high-flow oxygen & 5 \\
Intubation and mechanical ventilation. & 6 \\
Mechanical ventilation + additional organ support: & 7 \\
ECMO, CRRT, vasopressors. & 8 \\
Death &
\end{tabular}

ECMO extracorporeal membrane oxygenation, CRRT continuous renal replacement therapy comparison of proportions (chi-square) was used for the percentage incidence of radiological findings, and the Mann-Whitney $U$ test was used for the date ranges. A significance level of $p<0.05$ was adopted.

The study was approved by the Emirates Institutional Review Board for COVID-19 Research (ID Ref: DOH/ CVDC/2020/1172). In accordance with the Declaration of Helsinki, study participants provided written informed consent (World Medical Association Declaration of Helsinki: Ethical Principles for Human Medical Research [Internet]. Vol. 310, JAMA-Journal of the American Medical Association. JAMA; 2013 [cited 2020 Oct 18]. P. 2191-4. Available from: https://pubmed.ncbi.nlm.nih. gov/24141714/) [15]. In the informed consent document, the importance of participation was highlighted and the characteristics of the study and the possible risks and benefits were explained. The patients signed the consent with full knowledge of it, as well as its risks and benefits; additionally, they approved the disclosure of laboratory results and images, as long as the protection of personal data was ensured. All data were kept confidential and the identity of the participants was unlinked. Additional data is available by sending an email to the corresponding author. The selection of diagnostic tools followed the ethical principles of maximum benefit and nonmaleficence. This manuscript has the approval of the ethical committee concerning publishing data derived from the main clinical trial. Our study adheres to $\mathrm{CON}$ SORT guidelines.

\section{Results}

A total of 139 patients were included in the study: 129 (93\%) males and 10 (7\%) females total, with 65 (94\%) males and 4 (6\%) females in group A and 64 (91\%) males and $6(9 \%)$ females in group B. The ages of group A ranged from 27 to 71 years (mean 45.9 years old) and from 26 to 73 years old in group B (mean 44.31 years 
old), with no significant differences between the two groups $(p=0.3677)$.

The median hospital stay after receiving the study treatment was 5 days for group A and 6 days for group $\mathrm{B}$ (control), but the range for group B was from 2 to 125 days compared to 1 to 43 days for group A ( $p=0.2924)$.

At the time of recruitment, a total of 40 CT scans (37 from group A and 3 from group B) and 100 CXR scans (32 from group $A$ and 68 from group $B$ ) were performed. The most common finding was GGOs, appearing in 91 of the cases and 89 of the controls ( $p=$ 0.6955 ), followed by consolidations in 25 of the cases and 26 of the controls $(p=0.9029)$, interlobular septal thickening $(p=0.5653)$, and pleural effusion ( $p=$ 0.2342 ), with $20 \%$ of patients in the control group having normal radiological findings despite being scored 3 from recruitment until discharge $(p=0.0001)$ (Fig. 2).

During follow-up, up to 5 imaging controls were made in group A and 6 in group B. The preferred technology was CXR, while non-contrast chest CT was used in $44 \%$ vs CXR in 50\% during the second control and 7\% vs 93\% in the third only in group A. In the first control after treatment or only recruitment, depending on the group, $22 \%$ of the reported patients showed favorable improvement in their radiological findings in group A vs $0 \%$ in group B $(p<$ 0.0001 ); in the third control, $19 \%$ of each group ( $p=$ 1.0000 ), in the fourth $40 \%$ from group A vs $0 \%$ from group B $(p<0.0001)$, and $100 \%$ in the fifth control of the remaining patients of each group. Only $6 \%$ of group A patients were reported to have lymphadenopathy $(p=0.382)$. GGOs persisted as the most common finding in all control images in both groups, followed by consolidations. No other findings were mentioned by the corresponding radiologist from the different hospitals, such as reticular patterns or pericardial effusion (Table 2).

We selected relevant images from the treatment group before and after the treatment, which are shown in Figs. 3,4, 5, 6 and 7 .

\section{Discussion}

In SARS-CoV-2 patients, a radiological imaging examination is a decisive tool for diagnosis, assessing disease severity and monitoring the clinical course, helping to reduce morbidity and mortality through early diagnosis, suitable treatment, and prevention of disease spread [16].

The RSNA Expert consensus document on reporting chest CT findings related to SARS-CoV-2 endorsed by the STR (Society of Thoracic Radiology) and ACR on 24 March 2020 [12] is shown in Fig. 8.

The level of suspicion for SARS-CoV-2according to the CT findings ranges from very low or CO-RADS 1 to very high or CO-RADS 5, and clinical severity is determined based on comorbidity and differential diagnosis data [17]. CO-RADS 1 has a high negative predictive value in patients with symptoms for four or more days, and CORADS 5 has a very high positive predictive value. However, interobserver variation for CO-RADS 2-4 is high and has a negative and poor predictive value. Therefore, interpretation of CT findings should be combined with clinical symptoms and duration, as $\mathrm{CT}$ can be negative during the first days of mild infection (Fig. 9).

Mesenchymal stem cells (MSCs) have immunomodulatory effects that can neutralize the intensified immune response and repair damaged and injured cells and tissues in the context of acute respiratory distress syndrome (ARDS). MSCs secrete multiple factors involved in the regeneration and modulation of tissue damage, such as epidermal growth factor (EGF), platelet-derived growth factor (PDGF), fibroblast growth factor (FGF), hepatocyte growth factor (HGF), vascular endothelial growth factor (VEGF) and insulin-like growth factor, and lung injury in vivo [7].

MSCs have been used to treat SARS-CoV-2 to reverse the cytokine storm [18-20]. These cells act in various processes of innate and adaptive immunity, which likely cause changes in the activation of the immune system in patients with inflammatory diseases and by stimulating secretion of anti-apoptotic and regenerative factors.

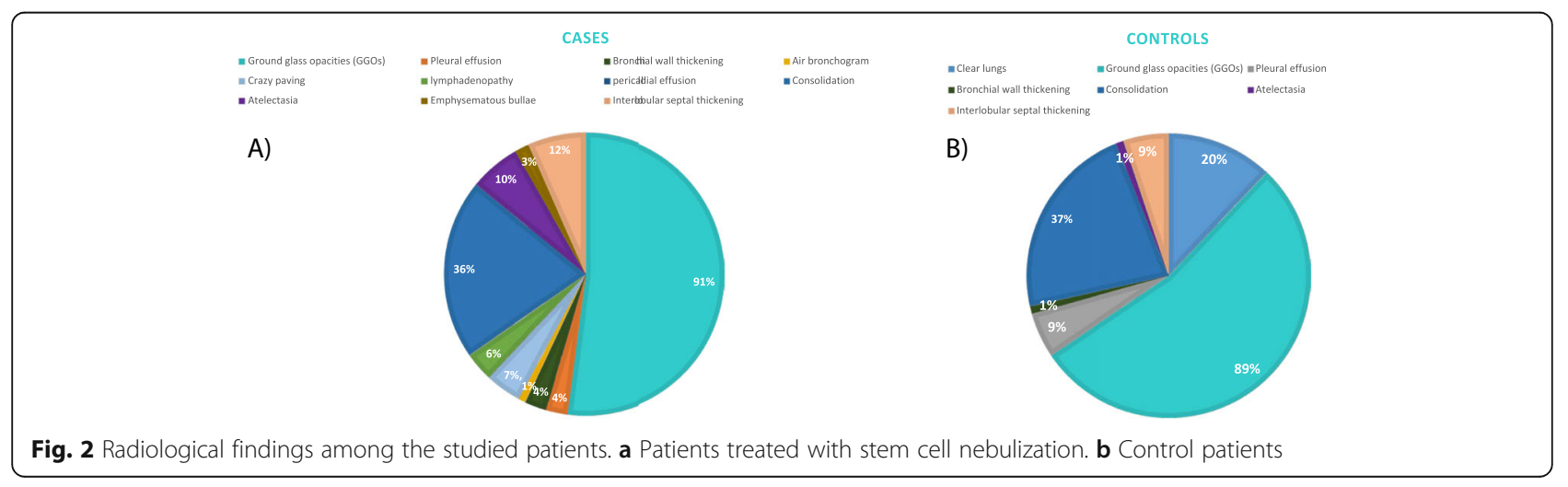




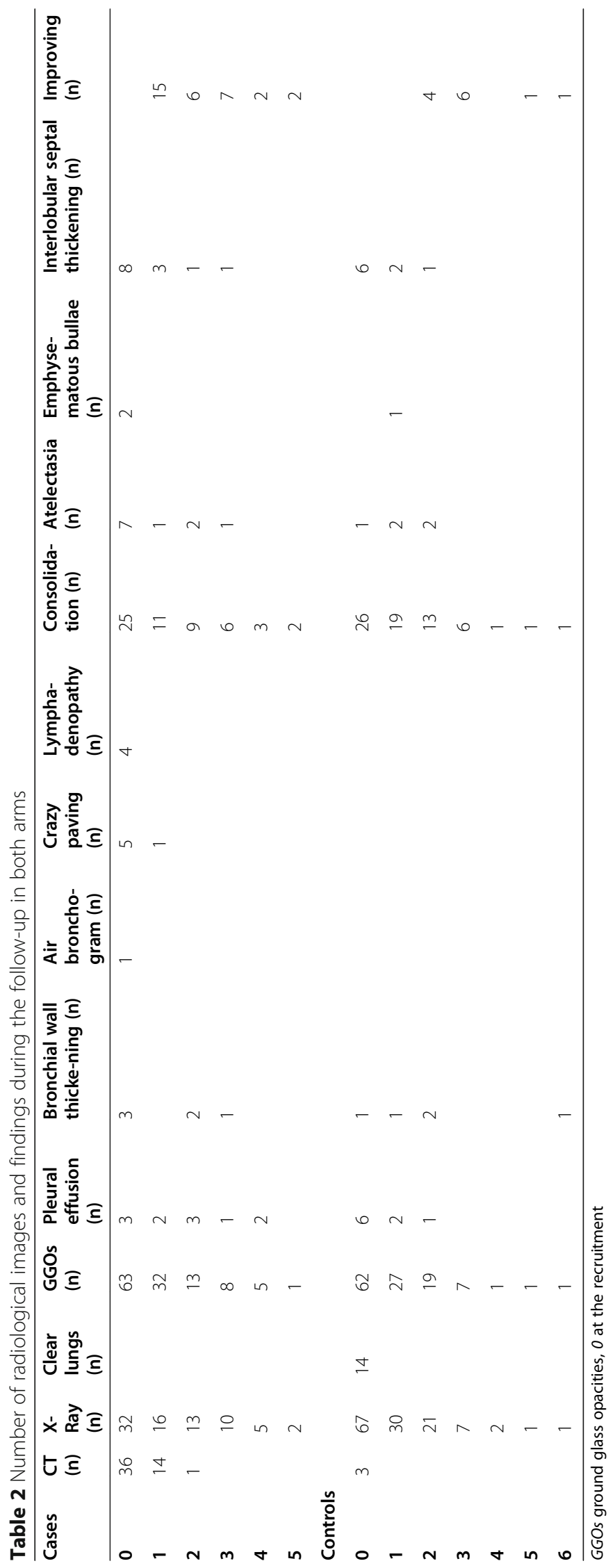




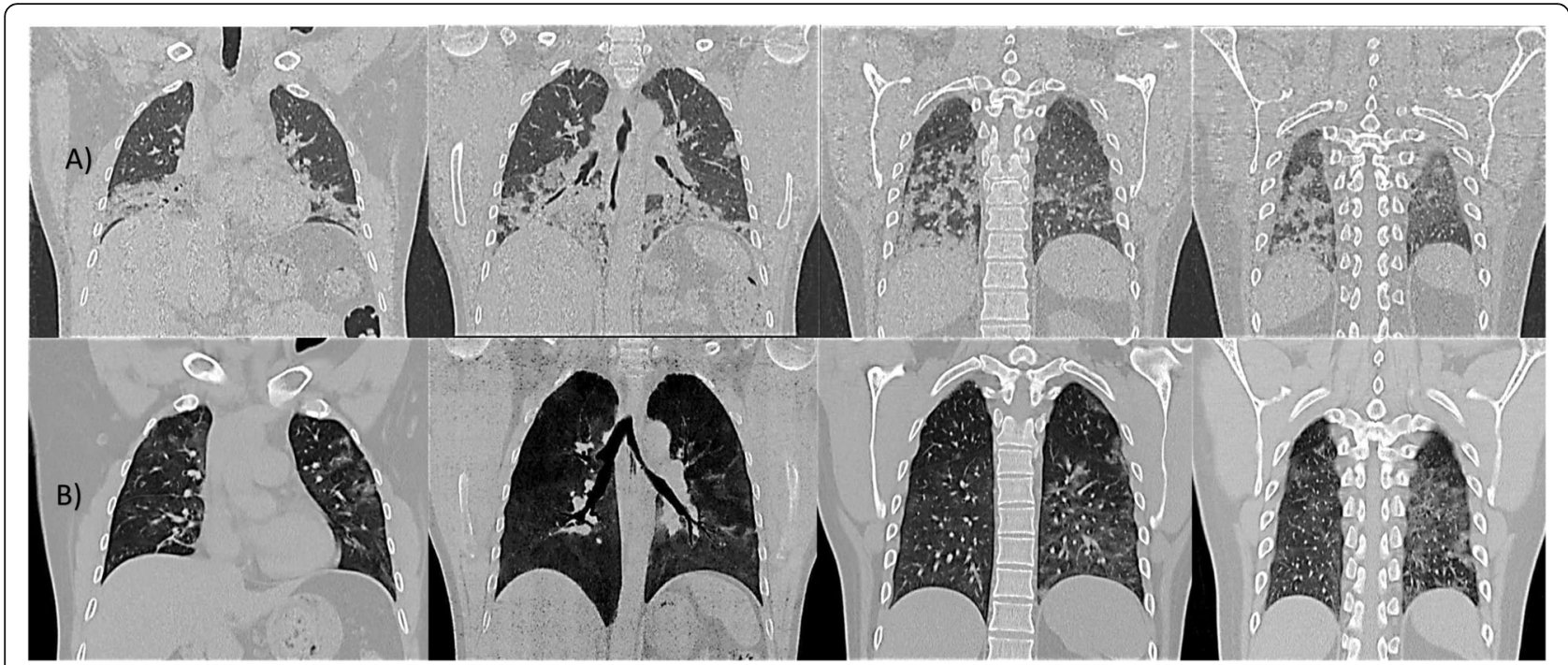

Fig. 3 Case 5: A 42-year-old male, without comorbidities, score 4 at the moment of the recruitment, with oxygen requirements through a nasal cannula. High-resolution CT chest: a day of admission (April 1st). There are right lung lower lobe and middle lobe extensive consolidations. Similar peripheral opacities noted in the left lung lower lobe and upper lobe. b Day 4 after treatment (April 13th, nebulization did on April 9th). Significant improvement of previously noted patchy consolidations at bilateral lower lobes and right middle lobe, as well as few peripheral consolidations in the left upper lobe

The number of MSC-based clinical trials in these SARS$\mathrm{CoV}-2$ subjects is increasing. To date, there are nearly 60 clinical, multi-phase trials evaluating MSC therapy in SARS-CoV-2 subjects listed on clinicaltrials.gov [21]. Most of these trials have not been published, as they are ongoing. According to 1 clinical study of 10 subjects with SARS-CoV-2 pneumonia, 7 were administered MSCs, while the remaining 3 were used as controls [21, 22]. MSC transplantation was safe, with no reports of infusionrelated effects or delayed hypersensitivity, and led to reduced serum CRP, the normalization of white blood cell counts, and symptomatic relief of pneumonia.

In this study, we identified a high incidence of GGOs and consolidations without differences between the two groups; corresponding to a meta-analysis, these findings were reported in $94.5 \%(52 / 55)$ of studies [11]. Our

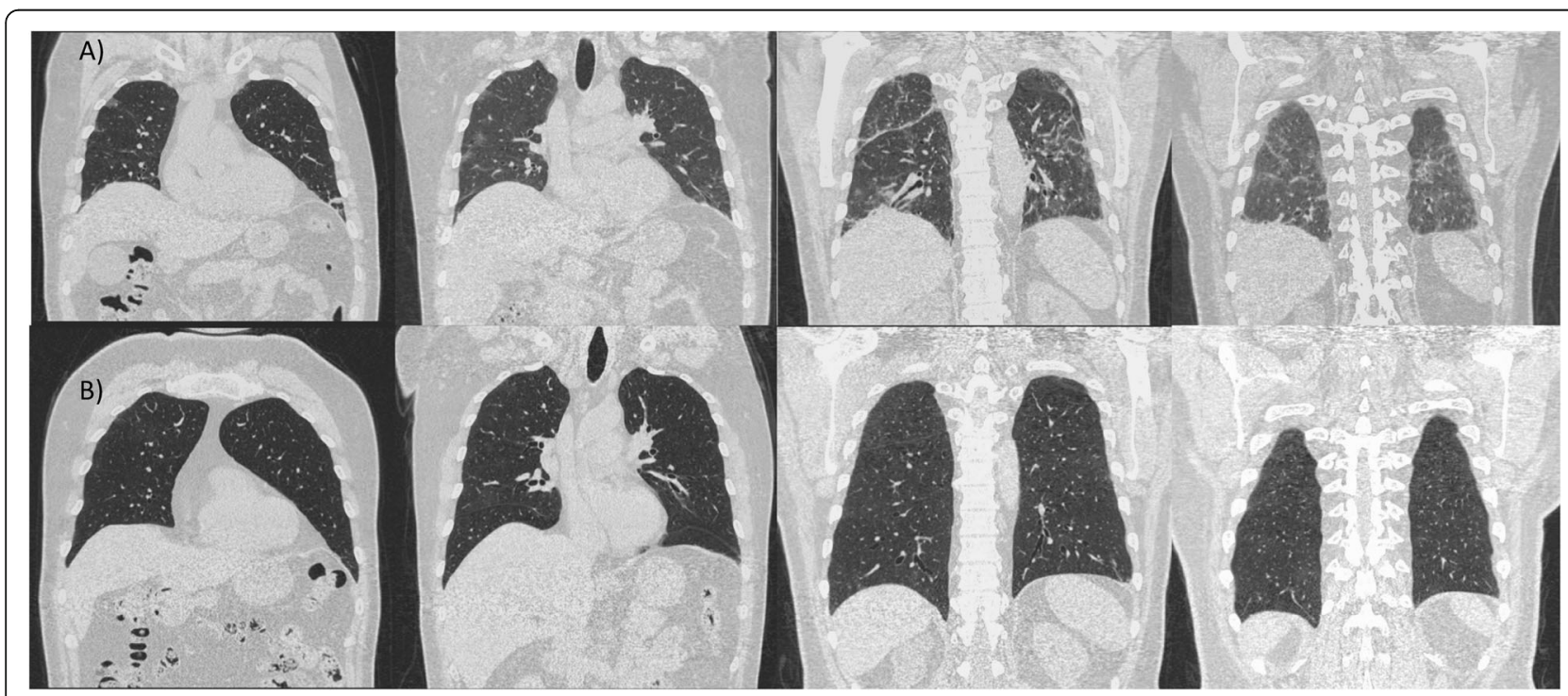

Fig. 4 Case 36: 58-year-old male with a history of hypertension, score 3 at the moment of inclusion. CT chest: a day of inclusion (April 11th). Bilateral multi-lobar multi-focal, peripheral and subpleural mixed attenuation groundglass, nodular, and linear opacities without crazy-paving pattern noted in bilateral lung parenchyma predominantly involving the bilateral lower lobes. $\mathbf{b}$ Day 8 after treatment on (April 21 st, nebulization did on April 13th). A few scattered areas of ground-glass shadowing in the bilateral lungs. Significant resolution compared to the previous examination 


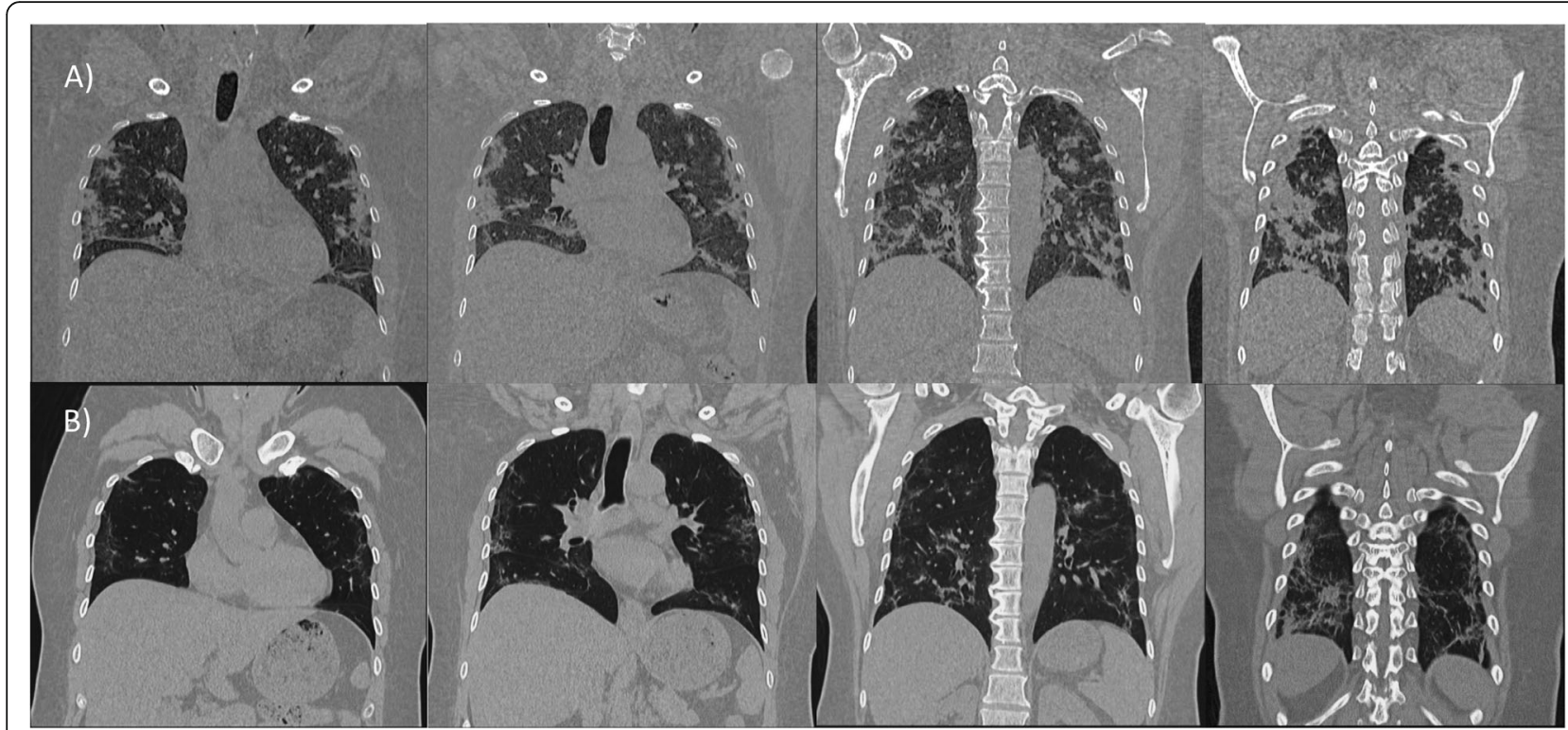

Fig. 5 Case 51: 44-year-old female (healthcare worker), with a history of hypertension and hypothyroidism under treatment, score 4. CT chest: a day of admission (April 14th). Multi-focal areas of ground-glass opacification/consolidation in the bilateral lungs-lesions. b Day 5 after treatment (April 20th). The ground-glass opacities and organized consolidation is seen previously in both lungs in subpleural and peripheral locations appear to be less dense with less size comparing with the previous study done on 14 April 2020 suggestive of good responding to treatment with markedly resolving disease

results suggest a significant improvement in radiological images in group A after treatment secondary to the stem cell effect on reducing inflammation and stimulating the pulmonological healing process. This method is already being used as a treatment option for lung inflammation via nebulization, with an increase in the number of lungs' endothelial cells, accelerating airway healing and favorably altering the pathophysiological changes [23].

Few stem cell therapy trials have been reported, most of which were performed by intravenous injection techniques and not by nebulization. Two studies described outcomes of SARS-CoV-2 patients who received umbilical cord-derived MSCs in different regimens. Zhang et al. infused a single dose of 1 million cells $/ \mathrm{kg}$ in a critically ill SARS-CoV-2 patient who significantly benefited from therapy and was discharged 7 days after the procedure [20]. Liang et al. treated a critically ill SARS$\mathrm{CoV}-2$ patient unresponsive to prior glucocorticoids, antivirals, and antibiotics with a dose of three 50 million MSCs. No adverse effects were observed, and the patient presented clinical and biomarker improvement after the second cellular infusion [24].

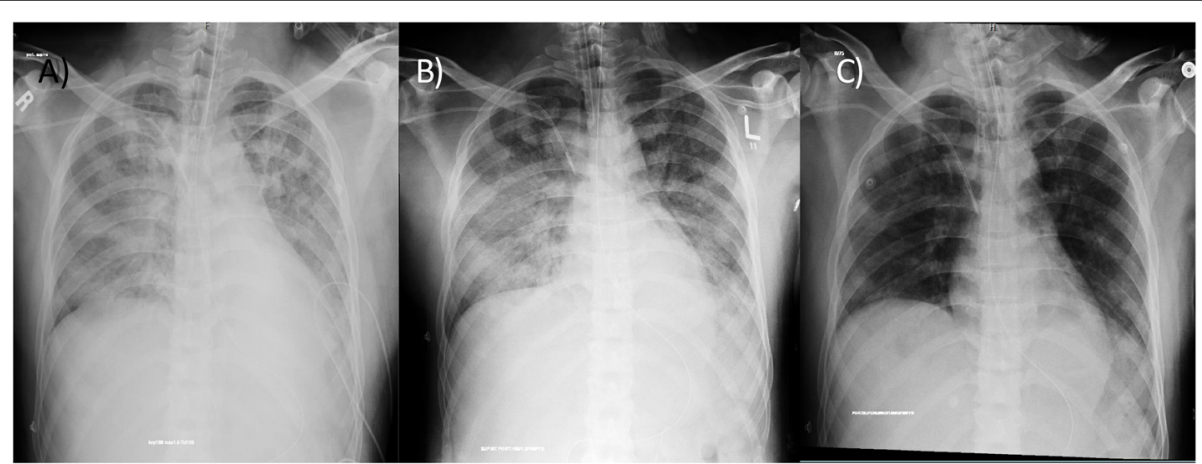

Fig. 6 Case 65: a 38-year-old male, with mild obesity, no other comorbidities, score 7 under vasopressor treatment. Chest X-ray: a day of inclusion (April 16th). Extensive consolidations involving both lung fields with left retrocardiac volume loss. Blunting of the left CP angle. III-defined opacities seen in bilateral lower zones. b Day 4 after treatment (April 20th). Improved appearance of patchy airspace opacity in the whole left lung with almost resolved bilateral pleural effusion and underlying atelectasis; however, consolidation is again noted in the left retrocardiac area with mild worsening of airspace opacity in the right mid and lower zones. c Day 9 after treatment (April 25th). Regression of patchy airspace opacification mid-right and left lung when compared to the previous study. Residual patchy bilateral airspace opacification particularly in the left retrocardiac region 


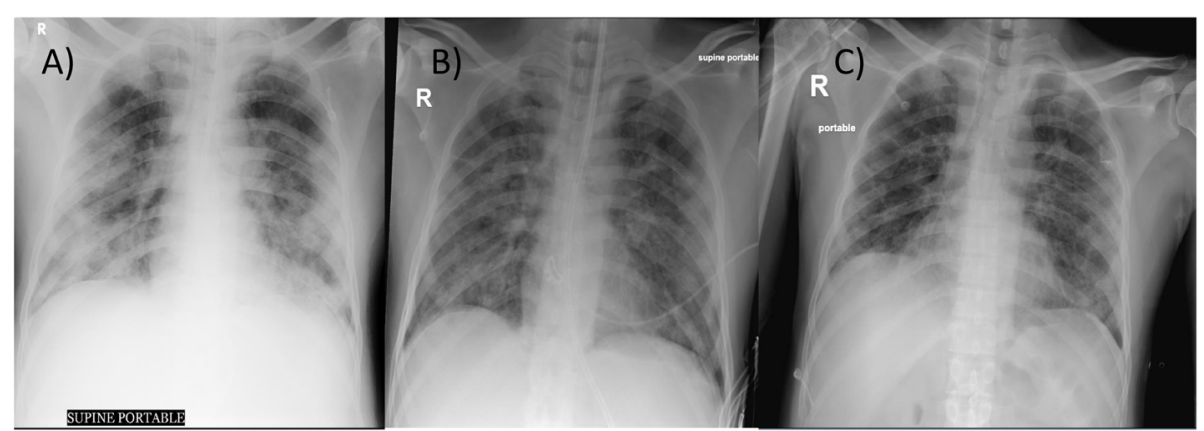

Fig. 7 Case 70: 47-year-old male, overweight (BMI 27.88) stayed at the ICU for 14 days, score 7, initially intubated, with post-critical polyneuropathy and grown Staphylococcus epidermidis Isolated from blood culture, resistant to Benzylpenicillin, Clindamycin, Erythromycin, Fusidic Acid, Oxacillin, Trimethoprim/Sulfa. Chest X-ray: a day of admission (April 17th). Extensive areas of diffusely organized consolidation throughout both lungs in all lobes, almost involving most of the lower lobes. b Day 4 after treatment (April 21st). X-ray partial resolution of the disease noted. c Day 13 after treatment (April 30th). Bilateral patchy opacities with mid to lower lung zone predominance as compared with previous partial resolution of the disease noted

Leng et al. conducted a pilot trial designed in parallel in seven critical patients with SARS-CoV-2 pneumonia treated with intravenous administration of human MSCs and a control group with three patients. Reportedly, treated patients showed relief of all symptoms 2 to 4 days after receiving MSC infusion with no apparent adverse effects. These findings were supported by decreased pneumonia infiltration indicated on chest CT scan and negative results of the SARS-CoV-2 nucleic acid test 2 weeks after infusion [19].

Previously, within the framework of this clinical trial, we examined the frequency of acute kidney injury (ARI) in patients with SARS-CoV-2 and its relationship with clinical outcomes, finding it in approximately one-third of critically ill patients [7]. In addition, those who received the treatment showed a tendency to improve in terms of hospital stay and the evolution of biomarkers (amelioration of lymphopenia $[8,18,25]$, neutrophillymphocyte ratio [26-29], and C-reactive protein (CRP)) compared to those in the control group. Likewise, we identified stem cells as a protective factor against secondary infection in SARS-CoV-2 cases in terms of sepsis and UTI, also finding an indiscriminate and massive use of antimicrobial agents, which is why rational use of these agents is needed.

The fact that the range in hospital stay after the intervention was much shorter in group A than in group B, given the homogeneity of the treated group thanks to

\begin{tabular}{|c|c|c|c|}
\hline \multicolumn{4}{|c|}{$\begin{array}{l}\text { COVID-19: Structured Reporting for Chest CT } \\
\text { RSNA Expert Consensus Document on Reporting Chest CT } \\
\text { findings related to COVID-19. Endorsed by the STR \& ACR 2/21/2020 }\end{array}$} \\
\hline Classification & Rationale & CT Findings & Suggested Reporting Language \\
\hline Typical & $\begin{array}{c}\text { Commonly reported } \\
\text { imaging features of } \\
\text { greater specificity for } \\
\text { COVID-19 } \\
\text { pneumonia }\end{array}$ & $\begin{array}{l}\text { * Peripheral, bilateral (multilobar), GGO w/ or w/o } \\
\text { consolidation or visible intralobular lines ("crazy paving"). } \\
\text { * Multifocal GGO of rounded morphology w/ or w/o } \\
\text { consolidation or visible intralobular lines ("crazy paving"). } \\
\text { * Reverse halo sign or other findings organizing pneumonia } \\
\text { (seen later in the disease). }\end{array}$ & $\begin{array}{c}\text { Commonly reported imaging features of (COVID-19) } \\
\text { pneumonia are present. Other processes such as } \\
\text { influenza pneumonia and organizing pneumonia, as } \\
\text { can be seen with drug toxicity and connective tissue } \\
\text { disease, can cause a similar imaging pattern } \\
\text { (Cov19Typ) }\end{array}$ \\
\hline Indeterminate & $\begin{array}{c}\text { Nonspecific imaging } \\
\text { features of COVID-19 } \\
\text { pneumonia }\end{array}$ & $\begin{array}{l}\text { Absence of typical features AND presence of: } \\
\text { * Multifocal, diffuse, perihilar or unilateral GGO w/ or w/o } \\
\text { consolidation, laking a specific distribution, \& are } \\
\text { nonrounded or non-peripheral. } \\
\text { * Few very small GGO w/ or w/o peripheral distribution. }\end{array}$ & $\begin{array}{c}\text { Imaging features can be with (COVID-19) pneumonia, } \\
\text { though are nonspecific and can occur with a variety of } \\
\text { infections and noninfectious processes (Cov19ind) }\end{array}$ \\
\hline Atypical & $\begin{array}{c}\text { Uncommonly of not } \\
\text { reported features of } \\
\text { COVID-19 } \\
\text { pneumonia }\end{array}$ & $\begin{array}{l}\text { Absence of typical or indeterminate features AND presence } \\
\text { of: } \\
\text { Isolated lobar or segmental consolidation } \mathrm{w} / \mathrm{o} \mathrm{GGO} \\
* \text { Discrete small nodules (centrilobular, tree-in-bud). } \\
\text { * Lung cavitation. } \\
\text { * Smooth interlobular septal thickening } \mathrm{w} / \text { pleural effusion }\end{array}$ & $\begin{array}{l}\text { Imaging features are atypical or uncommonly } \\
\text { reported for (COVID-19) pneumonia. Alternative } \\
\text { diagnoses should be considered. (Cov19ATY) }\end{array}$ \\
\hline Negative & $\begin{array}{l}\text { No features of } \\
\text { pneumonia }\end{array}$ & * No CT features to suggest pneumonia & $\begin{array}{c}\text { No CT findings present to indicate pneumonia. (Note: } \\
\text { CT may be negative in the early stages of COVID-19) } \\
\text { (Covi19Neg) }\end{array}$ \\
\hline
\end{tabular}

Fig. 8 American College of Radiology (ACR) Recommendations for the use of chest radiography and computed tomography (CT) for suspected COVID-19 infection 


\begin{tabular}{|c|c|c|}
\hline \multicolumn{3}{|c|}{$\begin{array}{l}\text { CO-RADS* } \\
\text { Level of suspicion COVI-19 infection }\end{array}$} \\
\hline & & CT Findings \\
\hline CO-RADS 1 & No & $\begin{array}{c}\text { Normal or non-infectious } \\
\text { abnormalities }\end{array}$ \\
\hline CO-RADS 2 & Low & $\begin{array}{l}\text { Abnormalities consistent with } \\
\text { infections other than COVID-19 }\end{array}$ \\
\hline CO-RADS 3 & Indeterminate & $\begin{array}{c}\text { Unclear whether COVID-19 is } \\
\text { present }\end{array}$ \\
\hline CO-RADS 4 & High & $\begin{array}{l}\text { Abnormalities suspicious for } \\
\text { COVID-19 }\end{array}$ \\
\hline CO-RADS 5 & Very High & Typical COVID-19 \\
\hline CO-RADS 6 & PCR + & \\
\hline
\end{tabular}

Fig. 9 CORADS classification for the level of suspicion of COVID-19 infection based on the CT findings

the therapy, and the statistical dispersion of the control group data, although the median was not significant between the groups, may explain why there were fewer radiological controls in the treated group since shorter hospital stay is a protective factor against additional complications and nosocomial infections [7, 30,31].

Following international recommendations, public hospitals in Abu Dhabi performed most of the radiographic control with CXR [30] due to infection control issues related to transporting patients to CT rooms for SARS$\mathrm{CoV}-2$ cases. It was also suggested that portable chest radiography should be considered to minimize the risk of cross-infection and in settings with limited access to the reliable real-time reverse transcription-polymerase chain reaction (RT-PCR) test [12]. Additionally, a positive CXR may avoid the need for a CT scan, minimizing radiation exposure.

\section{Conclusions}

In our study, patients in the treatment group exhibited a tendency to improve more rapidly with respect to chest radiological images. CXR itself is not diagnostic but does help with clinical suspicion while awaiting PCR results. The latest ACR appropriateness criteria should be considered, keeping in mind that the findings are nonspecific and overlap with other viral infections, such as H1N1, SARS, and MERS. The possible immunomodulatory effect of stem cells offers a therapeutic strategy to control the disease and avoid several associated complications, making it a crucial and potentially promising adjuvant tool for curing and achieving early recovery from SARS-CoV-2, especially in severe infections. The use of novel therapies, such as stem cells, has shown efficacy not only in terms of the control of clinical and paraclinical signs but also in terms of radiographic changes described in the disease; however, larger-scale studies are warranted for further assessment of the radiological correlation with the clinical condition of SARS-CoV-2 patients pre- and post-stem cell administration.

\section{Abbreviations}

ACR: American College of Radiology; ADSCC: Abu Dhabi Stem Cell Centre; AIDS: Acquired immunodeficiency syndrome; ARDS: Acute respiratory distress syndrome; BMI: Body mass index; CT: Computed tomography; CXR: Chest Xray; CRRT: Continuous renal replacement therapy; ECMO: Extracorporeal membrane oxygenation; EGF: Epidermal growth factor; DOH: Department of Health; FGF: Fibroblast growth factors; GGOs: Ground glass opacities; H1N1: Hemagglutinin type 1 and neuraminidase type 1; HBV: Hepatitis B virus; HGF: Hepatocyte growth factor; HIV: Human immunodeficiency virus; MERS: Middle East respiratory syndrome; MSCs: Mesenchymal stem cells; SARS: Severe acute respiratory syndrome; SARS-CoV-2: Severe acute respiratory syndrome coronavirus 2; PDGF: Platelet-derived growth factor; PBNHESC: Peripheral blood non-hematopoietic enriched stem cells; RTPCR: Reverse transcription polymerase chain reaction; UAE: United Arab Emirates; VEGF: Vascular endothelial growth factor; VSELs: Very small embryonic-like stem cells; WHO: World Health Organization

\section{Acknowledgements}

Acknowledgment to the government of the United Arab Emirates and especially to the Abu Dhabi Health Services Company SEHA for the contribution and support to this study. 


\section{Authors' contributions}

TZGM: conception and design, analysis and interpretation of data, drafting of the manuscript, and statistical analysis. MAY: supervision and drafting of the manuscript. YVC: supervision, administrative support. EEM: drafting of the manuscript. All authors participated in the critical revision of the manuscript for important intellectual content. All authors have read and approved the manuscript. Likewise, all the co-authors gave their approval for its publication.

\section{Funding}

This work was supported by ADSCC. This research had not received any other specific grant from any funding agency in the public, commercial, or not-for-profit sectors. Award/grant number is not applicable.

\section{Availability of data and materials}

No data is available due to the patient data protection law.

\section{Declarations}

\section{Ethics approval and consent to participate}

The study was approved by the Emirates Institutional Review Board for COVID-19 Research (ID Ref: DOH/CVDC/2020/1172). In accordance with the Declaration of Helsinki, study participants provided written informed consent (World Medical Association Declaration of Helsinki: Ethical Principles for Human Medical Research [Internet]. Vol. 310, JAMA-Journal of the American Medical Association. JAMA; 2013 [cited 2020 Oct 18]. P. 2191-4. Available from: https://pubmed.ncbi.nlm.nih.gov/24141714/). In the informed consent document, the importance of participation was highlighted and the characteristics of the study and the possible risks and benefits were explained. All data were kept confidential and the identity of the participants was unlinked. Additional data is available by sending an email to the corresponding author. The selection of diagnostic tools followed the ethical principles of maximum benefit and non-maleficence. This manuscript has the approval of the ethical committee concerning publishing data derived from the main clinical trial.

\section{Consent for publication}

The patients signed the consent with full knowledge of it, as well as its risks and benefits; additionally, they approved the disclosure of laboratory results and images, as long as the protection of personal data was ensured.

\section{Competing interests}

None of the contributing authors have any conflicts of interest.

\section{Received: 30 January 2021 Accepted: 7 April 2021}

\section{Published online: 28 April 2021}

\section{References}

1. WHO Coronavirus Disease (COVID-19) Dashboard / WHO coronavirus disease (COVID-19) Dashboard. https://covid19.who.int/. Accessed 14 Dec 2020.

2. National Clinical Committee for COVID-19 Management (2020) National Guidelines for Clinical Management and Treatment of COVID-19 1 st June, 2020 Version 4.0. United Arab Emirates Minist Heal 19(V4):1-61 https://www. dha.gov.ae/en/HealthRegulation/Documents/National_Guidelines_of_ COVID 19 1st_June 2020.pdf

3. Ioannis Kokkinakis, Kevin Selby, Bernard Favrat, Blaise Genton, Cornuz, J. [Covid-19 diagnosis : clinical recommendations and performance of nasopharyngeal swab-PCR] - PubMed. rev med suiss. Published 2020. https:/pubmed.ncbi.nlm.nih.gov/32270938/. Accessed 3 Jan 2021.

4. Wikramaratna PS, Paton RS, Ghafari M, Lourenço J (2020) Estimating the false-negative test probability of SARS-CoV-2 by RT-PCR. Eurosurveillance 25(50). https://doi.org/10.2807/1560-7917.ES.2020.25.50.2000568

5. Kucirka LM, Lauer SA, Laeyendecker O, Boon D, Lessler J (2020) Variation in false-negative rate of reverse transcriptase polymerase chain reaction-based SARS-CoV-2 tests by time since exposure. Ann Intern Med. 173(4):262-267. https://doi.org/10.7326/M20-1495

6. Gralinski LE, Menachery VD (2020) Return of the coronavirus: 2019-nCoV. Viruses 12(2). https://doi.org/10.3390/v12020135

7. Torres Zambrano GM, Valverde CAV, Hernandez AB, Hadi LA, Rivero RA, Carmenate YV Renal involvement in patients with COVID-19 pneumonia and outcomes after stem cell nebulization. medRxiv. Published online
December 18, 2020:2020.12.16.20236877. https://doi.org/10.1101/2020.12.1 6.20236877

8. Lippi G, Plebani M (2020) Laboratory abnormalities in patients with COVID2019 infection. Clin Chem Lab Med. 58(7):1131-1134. https://doi.org/10.151 5/cclm-2020-0198

9. Li Q, Guan X, Wu P, Wang X, Zhou L, Tong Y, Ren R, Leung KSM, Lau EHY, Wong JY, Xing X, Xiang N, Wu Y, Li C, Chen Q, Li D, Liu T, Zhao J, Liu M, Tu W, Chen C, Jin L, Yang R, Wang Q, Zhou S, Wang R, Liu H, Luo Y, Liu Y, Shao G, Li H, Tao Z, Yang Y, Deng Z, Liu B, Ma Z, Zhang Y, Shi G, Lam TTY, Wu JT, Gao GF, Cowling BJ, Yang B, Leung GM, Feng Z (2020) Early transmission dynamics in Wuhan, China, of Novel Coronavirus-Infected Pneumonia. N Engl J Med. 382(13):1199-1207. https://doi.org/10.1056/nejmoa2001316

10. Zhu N, Zhang D, Wang W, Li X, Yang B, Song J, Zhao X, Huang B, Shi W, Lu $R$, Niu P, Zhan F, Ma X, Wang D, Xu W, Wu G, Gao GF, Tan W, China Novel Coronavirus Investigating and Research Team (2020) A novel coronavirus from patients with pneumonia in China, 2019. N Engl J Med. 382(8):727733. https://doi.org/10.1056/nejmoa2001017

11. Sun Z, Zhang N, Li Y, Xu X (2020) A systematic review of chest imaging findings in COVID-19. Quant Imaging Med Surg 10(5):1058-1079. https://doi. org/10.21037/QIMS-20-564

12. ACR Recommendations for the use of Chest Radiography and Computed Tomography (CT) for Suspected COVID-19 Infection | American College of Radiology. Published 2020. https://www.acr.org/Advocacy-and-Economics/A CR-Position-Statements/Recommendations-for-Chest-Radiography-and-CTfor-Suspected-COVID19-Infection. Accessed 15 Dec 2020.

13. Study evaluating the safety and efficacy of autologous non-hematopoietic peripheral blood stem cells in COVID-19 - full text view - ClinicalTrials.gov. https://clinicaltrials.gov/ct2/show/study/NCT04473170?term=stem+ cell\&cond=covid \&cntry=AE\&draw $=2 \&$ rank=1. Accessed 18 Oct 2020

14. WHO R\&D Blueprint Novel Coronavirus COVID-19 Therapeutic Trial Synopsis.; 2020.

15. WorldMedical Association declaration of Helsinki (2013) Ethical principles for medicalresearch involving human subjects. JAMA 10(20):2191-2194. https:// doi.org/10.1001/jama.2013.281053

16. Yang W, Sirajuddin A, Zhang X, Liu G, Teng Z, Zhao S, Lu M (2020) The role of imaging in 2019 novel coronavirus pneumonia (COVID-19). Eur Radiol. 30(9):4874-4882. https://doi.org/10.1007/s00330-020-06827-4

17. The Radiology Assistant : COVID-19 CO-RADS classification. https://ra diologyassistant.nl/chest/covid-19/corads-classification. Accessed 3 Jan 2021.

18. Frater JL, Zini G, d'Onofrio G, Rogers HJ (2020) COVID-19 and the clinical hematology laboratory. Int J Lab Hematol. 42(S1):11-18. https://doi.org/1 $0.1111 /$ ijlh.13229

19. Leng Z, Zhu R, Hou W et al (2020) Transplantation of ACE2- Mesenchymal stem cells improves the outcome of patients with covid-19 pneumonia. Aging Dis 11(2):216-228. https://doi.org/10.14336/AD.2020.0228

20. Zhang W, Du RH, Li B et al (2020) Molecular and serological investigation of 2019-nCoV infected patients: implication of multiple shedding routes. Emerg Microbes Infect. 9(1):386-389. https://doi.org/10.1080/22221751.2020.1729071

21. Saldanha-Araujo F, Melgaço Garcez E, Silva-Carvalho AE, Carvalho JL (2020) Mesenchymal Stem Cells: A New Piece in the Puzzle of COVID-19 Treatment. Front Immunol. 11:1563. https://doi.org/10.3389/fimmu.2020.01563

22. Robert Chunhua Zhao RJ. 中国临床试验注册中心Chinese Clinical Trial Register (ChiCTR) - 世界卫生组织国际临床试验注册平台一级注册机构。 http://www.chictr.org.cn/historyversionpuben.aspx?regno=ChiCTR200002 9990. Accessed 5 Jan 2021.

23. Salama S, Kamel I, Ghanim M, Elsherif A (2019) The Efficacy of Autologous Nebulized Platelet Rich Plasma (PRP) As an Early Adjuvant Therapeutic and Prognostic Treatment Modality in the Management of Inhalation Lung Injury. Egypt J Plast Reconstr Surg 43(2):203-208. https://doi.org/10.21608/ ejprs.2019.65115

24. Liang J, Zhang H, Hua B, Wang H, Lu L, Shi S, Hou Y, Zeng X, Gilkeson GS, Sun $L$ (2010) Allogenic mesenchymal stem cells transplantation in refractory systemic lupus erythematosus: A pilot clinical study. Ann Rheum Dis. 69(8): 1423-1429. https://doi.org/10.1136/ard.2009.123463

25. Fan BE, Chong VCL, Chan SSW, Lim GH, Lim KGE, Tan GB, Mucheli SS, Kuperan P, Ong KH (2020) Hematologic parameters in patients with COVID-19 infection. Am J Hematol. 95(6):E131-E134. https://doi.org/10.1002/ajh.25774

26. Akilli NB, Yortanli M, Mutlu H et al (2014) Prognostic importance of neutrophil-lymphocyte ratio in critically ill patients: Short- and long-term outcomes. Am J Emerg Med. 32(12):1476-1480. https://doi.org/10.1016/j.a jem.2014.09.001 
27. Basbus L, Lapidus MI, Martingano I, Puga MC, Pollán J (2020) Neutrophil to lymphocyte ratio as a prognostic marker in COVID-19. Medicina (B Aires) 80(Suppl 3):31-36

28. Witjes JA, et al (2020) EAU Guidelines on Muscle-invasive and metastatic bladder cancer 2020. Eur Assoc Urol Guidel 2020 Ed., vol. presented, [Online]. Available: http://uroweb.org/quideline/bladder-cancer-muscle-invasive-andmetastatic/ LK - Muscle-invasive and Metastatic Bladder Cancer. ISBN 978-9492671-13-4. https://uroweb.org/guideline/bladder-cancer-muscle-invasive-andmetastatic/.

29. Ljungberg B, Albiges L, Bensalah K et al (2020) EAU Guidelines. Edn. presented at the EAU Annual Congress Amsterdam 2020. Eur Urol. 67(5):913-924

30. Jeon CY, Neidell M, Jia H, Sinisi M, Larson E (2012) On the role of length of stay in healthcare-associated bloodstream infection. Infect Control Hosp Epidemiol. 33(12):1213-1218. https://doi.org/10.1086/668422

31. Torres Zambrano GM, Rivero RA, Valverde CAV, Carmenate YV Features and outcomes of secondary sepsis and urinary tract infections in COVID-19 patients treated with stem cell nebulization. medRxiv. Published online December 7, 2020:2020.12.05.20244483. https://doi.org/10.1101/2020.12.05.2 0244483

\section{Publisher's Note}

Springer Nature remains neutral with regard to jurisdictional claims in published maps and institutional affiliations.

\section{Submit your manuscript to a SpringerOpen ${ }^{\circ}$ journal and benefit from:}

- Convenient online submission

- Rigorous peer review

- Open access: articles freely available online

High visibility within the field

- Retaining the copyright to your article

Submit your next manuscript at $\boldsymbol{\nabla}$ springeropen.com 